\title{
Multicriteria Optimal Selection of a Hydraulic Cylinder for Drive Mechanisms
}

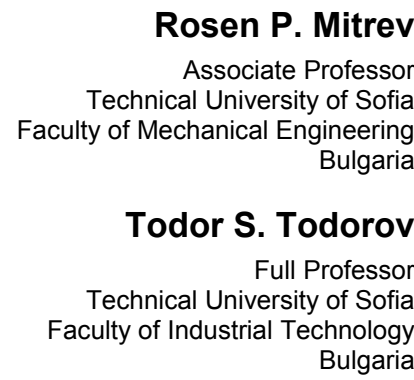

Rosen P. Mitrev

Associate Professo ineering Bulgaria

The paper reports the optimization synthesis of a hydraulically actuated drive mechanism. A mathematical model of the mechanism using vector closure equations is developed. Based on the functional purpose of the mechanism, a set of geometric and force/moment requirements are defined which must be met by a proper selection of a standardized hydraulic cylinder and its points of attachment. A multiobjective design optimization task is defined with three objective functions whose minimum is searchedthe mass of the hydraulic cylinder, the squared total deviation of the developed by the hydraulic cylinder moments from the predefined values of the external moments and the force in the hydraulic cylinder. The defined multiobjective optimization task is considered as a mixed variable nonlinear constrained optimization problem containing 5 continuous and 2 discrete variables and the multistage Monte Carlo method is used for its solution. Using different weighting schemes several Pareto-optimal compromise solutions are obtained.

Keywords: optimization, drive mechanism, continuous and discrete variables, Monte Carlo method.

\section{INTRODUCTION}

In modern society, along with the introduction of new technologies, there is an increasing trend to improve the characteristics of the existing products and devices. Especially of paramount importance is the optimization of the drive mechanisms used in the energy-intensive industrial equipment such as hydraulically driven manipulators - hydraulic excavators, truck-mounted cranes, mining and material handling machines etc. The optimization synthesis [1-3] is a key technique for designing mechanisms satisfying predefined geometric, force, mass, power etc. requirements. Using a suitable optimization method the dimensions of the mechanism links are determined to satisfy certain requirements, expressed by one or more objective functions, interval, and functional constraints. The optimization synthesis is applied successfully many times for obtaining competitive machines and mechanisms. The authors of [4] presented an optimal dimensional synthesis of the hydraulic excavator working mechanism performed using multiobjective optimization and achieved an improvement of the digging performance. The paper [5] presents a method for the selection of optimal transmission mechanism parameters of a hydraulic forest crane by the solution of an optimization task and thus the machine performance is enhanced. A systematic method for optimal component selection of electrohydraulic servo systems including hydraulic cylinders is presented in [6]. The paper [7] presents mathematical modelling and optimum synthesis of oscillating slide actuators used in

Received: February 2021, Accepted: March 2021

Correspondence to: Dr Rosen Mitrev, Associate

Professor, Technical University of Sofia, Faculty of

Mechanical Engineering, Bulgaria

E-mail: rosenm@tu-sofia.bg

doi:10.5937/fme2102501M

(C) Faculty of Mechanical Engineering, Belgrade. All rights reserved mechatronics devices. A complete methodology for optimal synthesis of drive mechanisms of hydraulic excavators taking into account the digging processes is developed in [8]. The authors of [9] developed a mathematical model of an excavator considering the kinematics of the links drive mechanisms.

A problem that has not been given enough attention in the existing research is the selection of a hydraulic cylinder, whose parameters largely determines the performance characteristics of the drive mechanism. Usually, this design task is related to the selection from a given finite discrete set, and most often it is a selection of a standardized in diameter and stroke hydraulic cylinders from a manufacturer's catalogue [10]. The optimization problems in which some of the design variables accept only discrete values are very common in engineering. Over the last few decades, a large number of studies have been devoted to this problem $[11,12]$. The methods for solving optimization problems containing simultaneously continuous and discrete/integer variables are classified in [13] and depend mainly on the type of the objective function and design variables. Since in most cases it is difficult to achieve the optimal solution within one iteration, it is necessary to specify the solution in several consecutive steps, accompanied by decision-making and changing the parameters of the task. For this reason, the process of finding the optimal solution is iterative and has a certain degree of interactivity, i.e. the designer can influence the process of obtaining the final solution [14]. In all cases, finding the best feasible design is not guaranteed.

With a great application for solving mechanism dimensional synthesis the problems are the evolutionary algorithms [15], which have been implemented in dedicated software products [16]. Less commonly used, but with great potential in solving optimization problems 
with mixed variables is the Monte Carlo method based on the multiple evaluations of the objective function value for randomly generated sets of values of the design variables [17]. The effectiveness of the Monte Carlo method is considerably increased when it is applied in several consecutive stages with successive narrowing of the search region based on the previous stage results $[18,19]$. The Parameter Space Investigation method has the same conceptual simplicity, but it is not based on the generation of uniformly distributed random numbers but the use of quasi-random $\mathrm{LP}_{\tau}$ sequences $[20,21]$. Both methods are very suitable for optimization of functions, in which numerical problems arise related to the presence of discrete variables, inability to differentiate functions etc. or when, in addition to the optimal solution, suboptimal solutions are also accepted for practical use.

The paper aims to develop a method for an optimal selection of a standardized hydraulic cylinder for a hydraulically actuated drive mechanism considering the multicriteria character of the problem. For the achievement of this goal, a kinematic model of the mechanism is developed and an optimization dimensional synthesis is performed using the multistage Monte Carlo method.

\section{KINEMATIC ANALYSIS OF THE HYDRAULI- CALLY ACTUATED MECHANISM}

The kinematics and force equations are derived for the case of a hydraulically actuated boom [22] with kinematic length $L$ lifting a payload with weight $G_{p}$, see Fig. 1 .

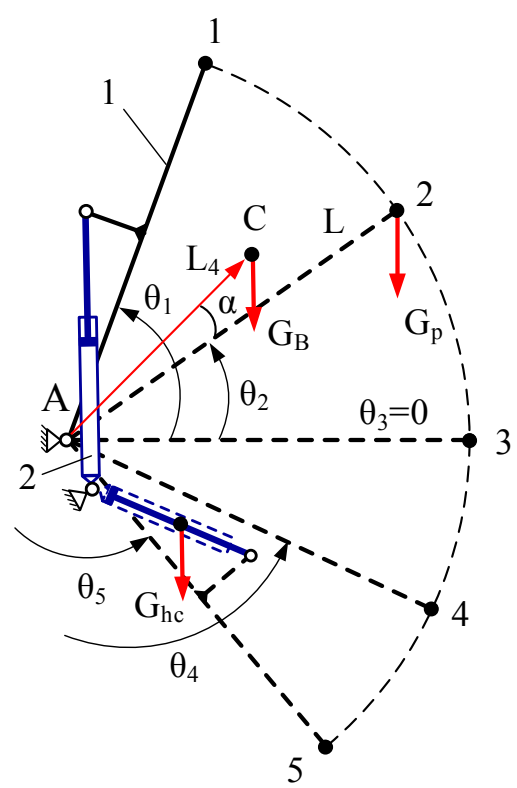

Figure 1. Graphical layout of the boom specific positions

Another two loads applied to the boom are: 1) The weight of the boom $G_{B}$ applied to its gravity center whose position is determined by the vector with length $L_{4}$ and angle $\alpha$; 2) The weight of the hydraulic cylinder $G_{h c}$, applied to its gravity center. In the current paper, for simplicity, it is considered that for every position gravity center of the hydraulic cylinder is situated in the middle of its current length. Another important assumption is that the movements of the mechanism are relatively slow and the inertia forces can be neglected.
Figure 1 shows five specific positions of the boom, determined by the corresponding angles $\theta_{i}(i=1, \ldots, 5)$ measured counterclockwise from the horizontal axis. The angles $\theta_{1}$ and $\theta_{5}$ correspond to the maximum and minimum angles of inclination of the boom respectively, and the angle $\theta_{3}$ corresponds to the horizontal position of the boom. The angles $\theta_{2}$ and $\theta_{4}$ are defined as averages between the horizontal and the maximum and the horizontal and minimum angles of the boom inclination, respectively.

Figure 2 depicts the schematic layout of the mechanism comprised of a hydraulic cylinder 1 and a boom 2 .

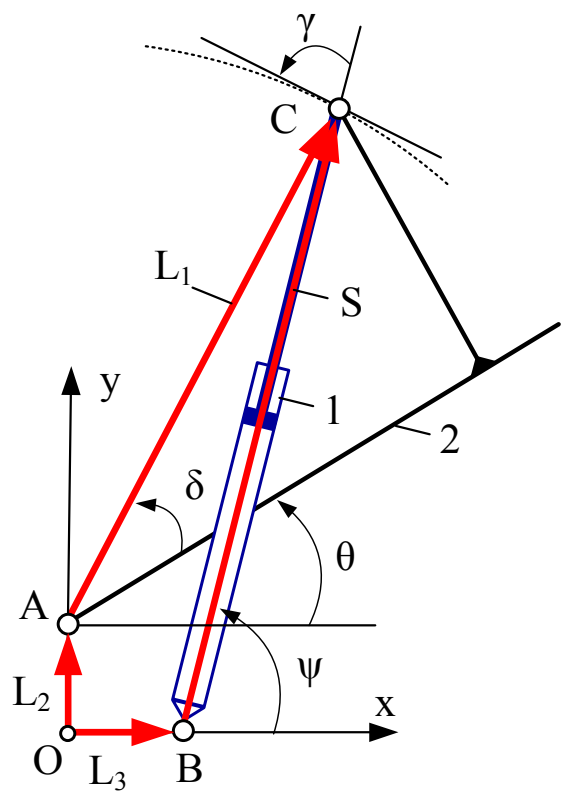

Figure 2. Schematic layout and vector closure diagram of the inverted slider-crank mechanism

By $\theta$ is denoted the current angle of rotation of the boom measured between the line representing the kinematical length of the boom and the horizontal axis. The mechanism is classified as an inverted slider-crank mechanism with input the changeable length of the hydraulic cylinder and output - the angle of rotation of the boom $\theta$.

The kinematic analysis of the mechanism is conducted using the vector closure diagram shown in Figure 2:

$$
\mathbf{L}_{2}+\mathbf{L}_{1}=\mathbf{L}_{3}+\mathbf{S}
$$

whose projections onto the fixed $\{x O y\}$ coordinate system are:

$$
\begin{aligned}
& L_{1} \cos (\delta+\theta)=L_{3}+S \cos \psi \\
& L_{2}+L_{1} \sin (\delta+\theta)=S \sin \psi
\end{aligned}
$$

After certain transformations and simplification, the equations (2) are presented as a single equation:

$$
K_{1} \cos \Delta+K_{2} \sin \Delta+K_{3}=0
$$

where the following notations are used: $K_{1}=-2 L_{1} L_{3}$, $K_{2}=2 L_{1} L_{2}, K_{3}=L_{1}^{2}+L_{2}^{2}+L_{3}^{2}-S^{2}, \Delta=\delta+\theta$.

The solution of this equation gives the following relation for the hydraulic cylinder length $S$ and the angle of the boom rotation $\theta$ : 


$$
S(\theta)=\sqrt{L_{1}^{2}+L_{2}^{2}+L_{3}^{2}+2 L_{1}\left(L_{2} \sin \Delta-L_{3} \cos \Delta\right)}
$$

Also, the angle of inclination $\psi$ of the hydraulic cylinder is calculated as:

$$
\psi=\operatorname{atan}_{2}\left(\frac{L_{1} \cos \Delta-L_{3}}{S}, \frac{L_{1} \sin \Delta+L_{2}}{S}\right)
$$

The hydraulic cylinder force $F_{h c}$ is transformed into an equivalent torque $M_{h c}$, applied in the joint $A$. Using the principle of virtual work, the mapping $T_{h c}\left(F_{h c}\right)$ is obtained:

$$
T_{h c}(\theta)=F_{h c} k(\theta)
$$

where $k(\theta)$ is the influence coefficient calculated as:

$$
k(\theta)=-L_{1} \sin (\delta+\theta-\psi)
$$

\section{DEFINITION OF FUNCTIONAL REQUIREMENTS FOR THE HYDRAULICALLY ACTUATED MECHANISM}

Based on the functional purpose of the considered hydraulically actuated mechanism, the coordinates of the points of attachment $C$ and $B$ and the standardized hydraulic cylinder parameters should be determined in such a way so that the predefined geometric and force /moment requirements are met.

\subsection{Geometric requirements}

The following two types of geometric conditions must be satisfied:

1) The stroke of the hydraulic cylinder should be determined in such a way so that the predefined values of the maximum $\theta_{1}$ and minimum $\theta_{5}$ angles of the link 2 rotation are achieved (see Fig.1). The angle $\theta_{l}$ is achieved for the maximum extended hydraulic cylinder with length $L_{h c}^{\max }$ :

$$
S\left(\theta_{1}\right)=L_{h c}^{\max }=L_{T}+2 h
$$

where $h$ denotes the stroke of the hydraulic cylinder and by $L_{T}$ is denoted the specific distance, computed as a difference between the length $L_{h c}^{\min }$ of the fully retracted cylinder and the stroke. Similarly, the angle $\theta_{5}$ is achieved at the maximum retraction of the hydraulic cylinder:

$$
S\left(\theta_{5}\right)=L_{h c}^{\min }=L_{T}+h
$$

In (8) and (9), $S\left(\theta_{1}\right)$ and $S\left(\theta_{5}\right)$ denote the maximum and the minimum lengths of the hydraulic cylinder, computed by (4).

2) The transmission angle $\gamma$ is defined as (see Figure 2):

$$
\gamma(\theta)=\frac{\pi}{2}+\delta+\theta-\psi
$$

must not exceed a predefined value $[\gamma]$. This requirement must be satisfied for the larger by the absolute value angle $\theta_{\max }=\max \left(\left|\theta_{1}\right|,\left|\theta_{5}\right|\right)$ :

$$
\gamma\left(\theta_{\max }\right) \leq[\gamma]
$$

\subsection{Force/moment requirements}

The defined geometric constraints are accompanied by the following force/moment constraints:

1) Moment constraints ensure the achievement of predefined moment values for the predefined angles of rotation. The moment $T_{h c}(\theta)$, developed by the hydraulic cylinder must overcome the total moment $M_{\text {ext }}(\theta)$ of the external forces about point $A$ (see Fig.1):

$$
T_{h c}(\theta) \geq M_{e x t}(\theta)
$$

For the considered hydraulically actuated boom the total external moment $M_{\text {ext }}(\theta)$ is calculated as a sum of the moments developed by the weights of the payload, boom and hydraulic cylinder (see Fig.1):

- Moment of the payload

$$
M_{p}(\theta)=G_{p} L \cos \theta
$$

- Moment of the boom

$$
M_{B}(\theta)=G_{B} L_{4} \cos (\alpha+\theta)
$$

where $G_{B}$ is the weight of the boom, $L_{4}$ and $\alpha$ are the length and the angle of rotation of the vector defining the position of the center of gravity of the boom, respectively;

- Moment of the hydraulic cylinder

$$
M_{h c}(\theta)=z \frac{m_{h c} g}{2} L_{1} \cos \Delta
$$

where $m_{h c}$ is the mass of the hydraulic cylinder; $z$ is the number of the connected in parallel hydraulic cylinders (typical values are $z=1$ or $z=2$ ); $g$ is the gravity acceleration.

The force $F_{h c}$ developed by the hydraulic cylinder is calculated as:

$$
F_{h c}=z p \frac{\pi \cdot D^{2}}{4} \eta
$$

where $p$ is the pressure in the hydraulic cylinder chamber; $D$ is the hydraulic cylinder piston diameter; $\eta$ is the hydraulic cylinder efficiency which takes into account the friction forces between the piston and body of the hydraulic cylinder, the pressure in the rod chamber, the friction moments in the hydraulic cylinder joints etc.

2) Force constraint imposed by the hydraulic cylinder buckling. The admissible force in the hydraulic cylinder is constrained by the buckling condition:

$$
F_{h c} \leq z\left[F_{b u c k}\right]
$$

where $\left[F_{b u c k}\right]$ is the admissible force in the hydraulic cylinder due to the buckling constraint [10]:

$$
\left[F_{b u c k}\right]=\left\{\begin{array}{l}
\frac{\pi^{2} E I}{v\left(L_{h c}^{\max }\right)^{2}}, \text { if } \lambda>\lambda_{g} \\
\frac{\pi d^{2}(335-0.62 \lambda)}{4 v}, \text { if } \lambda \leq \lambda_{g}
\end{array}\right.
$$


where $L_{h c}^{\max }$ (in $\mathrm{mm}$ ) is the free buckling length of the hydraulic cylinder; $\lambda$ is the slenderness ratio:

$$
\lambda=\frac{4 L_{h c}^{\max }}{d}
$$

$\lambda_{g}$ is the critical value of the slenderness ratio:

$$
\lambda_{g}=\pi \sqrt{\frac{E}{0.8 R_{e}}}
$$

Also, the following values of the constants are used: $E=2.1 \times 10^{5} \mathrm{MPa}$ is the modulus of elasticity for steel; $I=0.0491 \mathrm{~d}^{4}$ is the moment of inertia of circular crosssectional area, (in $\left.\mathrm{mm}^{4}\right) ; v=3.5$ is the safety factor; $d$ is the diameter of the piston rod (in mm); $R_{e}=400 \mathrm{MPa}$ is the yield strength of the piston rod material.

\section{DEFINITION OF A DESIGN OPTIMIZATION PROBLEM}

There is a great variety of technical aspects concerning the design of the considered mechanism. The solution of the task of hydraulic cylinder selection and its points of attachment is ambiguous due to the possibility to select more than one standardized hydraulic cylinders, satisfying with different degree of approximation the predefined requirements. Typically, the requirements for the diameter and stroke of the hydraulic cylinder to be simultaneously minimal are contradictory because moving the axis of the hydraulic cylinder away from the axis of rotation of the boom reduces its diameter but increases its stroke and vice versa. A multiobjective optimization task should be defined here, the solution of which will minimize both the stroke and the diameter of the hydraulic cylinder at the same time and will satisfy the defined geometric and force/moment requirements. The common characteristic combining the mentioned parameters is the working volume of the hydraulic cylinder whose minimal value is searched:

$$
V_{h c}=z h \frac{\pi \cdot D^{2}}{4}
$$

\subsection{Determination of design variables}

As design variables of the considered mechanism determining its output geometric and force/moment characteristics the following variables are considered:

$$
\mathbf{x}=\left[\begin{array}{lllllll}
L_{1} & L_{2} & L_{3} & \delta & p & D & h
\end{array}\right]^{T}
$$

where $L_{1}, L_{2}, L_{3}$ and $\delta$ are geometric variables (see Figure 2) determining the coordinates of the attachment points of the hydraulic cylinder; $p$ is the pressure in the hydraulic cylinder piston chamber; $D$ and $h$ are the piston diameter and the stroke of the hydraulic cylinder, correspondingly.

The variables $L_{1}, L_{2}, L_{3}, \delta$ and $p$ are considered as continuous in a predefined interval of values. The values of $D$ and $h$ are of discrete type and are determined by the standardized manufacturer's size range. Table 1 shows the numerical values of the following parameters of the range of standardized double-acting hydraulic cylinders: diameter $D$ of the piston; diameter $d$ of the piston rod; specific length $L_{t}$; basic mass $m_{b}$ of the cylinder body for stroke $h=0$; mass $m_{h}$ which must be added to the basic mass $m_{b}$ for every $1 \mathrm{~m}$ stroke.

Using the data from Table 1 the overall mass of a hydraulic cylinder with stroke $h$ is calculated as:

$$
m_{h c}=m_{b}+m_{h} h
$$

where the stroke $h$ is measured in meters.

\subsection{Definition of a multi-objective optimization problem}

Here, the optimization problem is considered as multiobjective [23] consisting of three objective functions.

The first objective function is defined from the consideration that the hydraulically actuated mechanism is a part of a mobile machine and minimum mass of the selected hydraulic cylinder is required:

$$
f_{1}(\mathbf{x})=z m_{h c} \rightarrow \min
$$

The mass of the hydraulic cylinder is proportional to its working volume (21) so the minimum of the mass will correspond to the minimum of the working volume. An additional important consideration is that the minimization of the mass improves the mechanical system dynamics and increases the tip-over stability of the machine [24].

Since it is necessary to achieve a certain degree of proximity of the moment $T_{h c}(\theta)$ developed by the hydraulic cylinder to the predefined external moments $M_{\text {ext }}\left(\theta_{i}\right)$ for five angles according to (12) and Figure 1, as a second objective function is accepted the squared total deviation of the developed by the hydraulic cylinder moments from the predefined values of the external moments:

$$
f_{2}(\mathbf{x})=\sum_{i=1}^{5}\left(T_{h c}\left(\theta_{i}\right)-M_{\text {ext }}\left(\theta_{i}\right)\right)^{2} \rightarrow \min
$$

As a third objective function defined by the mechanism links and supporting structure strength requirements was adopted the minimum of the force in the hydraulic cylinder:

Table 1. The size range of standardized double-acting hydraulic cylinders [10]

\begin{tabular}{|c|c|c|c|c|c|c|c|c|c|c|c|c|c|c|}
\hline № & 1 & 2 & 3 & 4 & 5 & 6 & 7 & 8 & 9 & 10 & 11 & 12 & 13 & 14 \\
\hline$D, \mathrm{~mm}$ & 40 & 50 & 63 & 80 & 100 & 125 & 140 & 160 & 180 & 200 & 220 & 250 & 280 & 320 \\
\hline$d, \mathrm{~mm}$ & 28 & 36 & 45 & 56 & 70 & 90 & 100 & 110 & 125 & 140 & 160 & 180 & 200 & 220 \\
\hline$L_{t}, \mathrm{~mm}$ & 482 & 505 & 570 & 620 & 695 & 790 & 860 & 930 & 1025 & 1090 & 1260 & 1300 & 1465 & 1630 \\
\hline$m_{b}, \mathrm{~kg}$ & 7 & 10 & 16 & 26 & 44 & 80 & 112 & 169 & 239 & 309 & 452 & 582 & 753 & 1125 \\
\hline$m_{h}, \mathrm{~kg}$ & 10 & 15 & 26 & 36 & 57 & 92 & 119 & 139 & 168 & 215 & 309 & 369 & 488 & 604 \\
\hline
\end{tabular}




$$
f_{3}(\mathbf{x})=F_{h c} \rightarrow \min
$$

Taking into account the defined geometric requirements $(8) \div(11)$, force/moment requirements $(12) \div(20)$ and the defined objective functions (24) $\div(26)$ the following optimization task is defined:

Minimize the set of objective functions

$$
f(\mathbf{x})=\left[f_{1}(\mathbf{x}), f_{2}(\mathbf{x}), f_{3}(\mathbf{x})\right]
$$

subject to the following set of:

- Functional constraints

$$
\begin{aligned}
& g_{1}(\mathbf{x}) \equiv\left|S\left(\theta_{1}\right)-L_{h c}^{\max }\right|-\varepsilon \leq 0 \\
& g_{2}(\mathbf{x}) \equiv\left|S\left(\theta_{5}\right)-L_{h c}^{\min }\right|-\varepsilon \leq 0 \\
& g_{3}(\mathbf{x}) \equiv \gamma\left(\theta_{\max }\right)-[\gamma] \leq 0 \\
& g_{4, \ldots, 8}(\mathbf{x}) \equiv M_{e x t}\left(\theta_{i}\right)-T_{h c}\left(\theta_{i}\right) \leq 0, i=1, \ldots, 5 \\
& g_{9}(\mathbf{x}) \equiv F_{h c}-z\left[F_{b u c k}\right] \leq 0
\end{aligned}
$$

- Interval constraints:

$$
\begin{aligned}
& L_{1}^{\min } \leq L_{1} \leq L_{1}^{\max }, L_{2}^{\min } \leq L_{2} \leq L_{2}^{\max } \\
& L_{3}^{\min } \leq L_{3} \leq L_{3}^{\max }, \delta_{2}^{\min } \leq \delta \leq \delta_{2}^{\max } \\
& p^{\min } \leq p \leq p^{\max }
\end{aligned}
$$

- Discrete variables $h$ and $D$.

For the definition of the constraint $g_{I}(\mathbf{x})$ corresponding to the maximum angle of rotation $\theta_{l}$ is accepted that when hydraulic cylinders with standardized discrete strokes are used it is not always possible to satisfy (8) exactly. Therefore an allowable deviation $\varepsilon$ between the theoretical length $S\left(\theta_{l}\right)$ and the length $L_{h c}^{\max }=L_{t}+2 h$ of the standardized hydraulic cylinder is defined. As a consequence of the presence of an allowable deviation, the required value of the angle $\theta_{l}$ will not be achieved, but for small $\varepsilon$ the error will be acceptable. The same considerations are used in defining the constraint $g_{2}(\mathbf{x})$ for the minimum angle of rotation $\theta_{5}$. Besides, the following values of the constants are used: $\theta_{1}=70^{\circ}$, $\theta_{2}=35^{0}, \quad \theta_{3}=0^{0}, \quad \theta_{4}=335^{\circ}, \quad \theta_{5}=310^{\circ},[\gamma]=85^{\circ}$, $\varepsilon=0.001 \mathrm{~m}, \quad G=50 \mathrm{kN}, \quad L=10 \mathrm{~m}, \quad \eta=0.95$, $G_{B}=10 \mathrm{kN}, L_{4}=4.2 \mathrm{~m}, \alpha=10^{0}$.

\section{NUMERICAL EXPERIMENTS AND DISCUSSION}

Many researchers applied a variety of optimization methods to improve the performance of systems with a different degree of complexity and belonging to different domains [25-28] using appropriate analytical and numerical tools [29]. The defined multiobjective optimization task (27) is considered as a mixed variable nonlinear constrained optimization problem containing 5 continuous and 2 discrete variables. For its solution is used the well-known Monte Carlo method based on uniform random sampling with a large number of trial points [18]. The steps of the method are as follows:

a) Specification of the number of trial points $n$; b) For $i=1$ to $n$ a trial point with coordinates $\mathbf{x}^{(i)}$ is generated:

$$
\mathbf{x}^{(i)}=\left(L_{1}^{(i)}, L_{2}^{(i)}, L_{3}^{(i)}, \delta^{(i)}, p^{(i)}, D^{(i)}, h^{(i)}\right)
$$

The values $C^{(i)}$ of the continuous variables for the trial point $i$ are computed as:

$$
C^{(i)}=C_{L}+\left(C_{U}-C_{L}\right) u^{(i)}
$$

where $C_{L}$ and $C_{U}$ denote the lower and upper bounds of the corresponding variable; $u^{(i)}$ denotes values of uniformly distributed random numbers between 0 and 1 different for each design variable to ensure their mutual independence.

The values of the discrete variables at step $i$ are randomly selected from vectors containing their discrete values. The position $f^{(i)}$ of the randomly selected discrete value in the vector with length $q$ is calculated as:

$$
f^{(i)}=\operatorname{round}\left[1+(q-1) u^{(i)}\right]
$$

where round denotes the rounding to the nearest integer;

c) If for the current trial point the constraints are satisfied then the values of the three objective functions are calculated and together with the coordinates of the corresponding trial points $\mathbf{x}^{(i)}$ are stored:

$$
f\left(\mathbf{x}^{(i)}\right)=\left[f_{1}\left(\mathbf{x}^{(i)}\right), f_{2}\left(\mathbf{x}^{(i)}\right), f_{3}\left(\mathbf{x}^{(i)}\right)\right]
$$

The set of the stored values $f\left(\mathbf{x}^{(i)}\right)$ satisfying the constraints represents a discrete approximation of the feasible space.

d) The optimal solution of the defined multiobjective optimization task consists not of a single point but of a set of points representing compromise solutions among the defined three objectives. This set is called Pareto front [23] and includes nondominated (efficient) solutions for which none of the three objectives can be improved without causing deterioration of the value of at least one of the other objectives. That's why after determination of the discrete feasible space a Pareto filter is applied to determine the points belonging to the Pareto front. Then by certain criteria, an optimal point from the obtained Pareto front is selected.

Typically, to discover the region in which the global optimum is located, one repeats the steps from a) to d) several times with decreased bounds of the design variables. The change of the bounds at each subsequent stage is based on the conducted analysis of the obtained Pareto front from the previous stage.

The choice of a single compromise point from the obtained Pareto front is based on the minimum value of the calculated squared distance $d^{2}$ between the normalized Utopia point and every point belonging to the Pareto front (Salukvadze optimal solution [30]):

$$
d^{2}=\sum_{l=1}^{3} w_{l}\left(f_{l}^{n}\right)^{2}
$$

where $w_{l}$ is the weighting coefficient serving as a quantitative expression of the importance of the $l$-th 
objective function. The weighting coefficients are positive, satisfying

$$
\sum_{l=1}^{3} w_{l}=1,0 \leq w_{l} \leq 1
$$

Also, in (34) $f_{l}^{n}$ denotes the value of the $l$-th normalized objective function:

$$
f_{l}^{n}=\frac{f_{l}-f_{l}^{\min }}{f_{l}^{\max }-f_{l}^{\min }}
$$

Table 2. Design variables bounds for Stage $I$

\begin{tabular}{|c|c|c|c|c|c|}
\hline & $\mathrm{L}_{1}, \mathrm{~m}$ & $\mathrm{~L}_{2}, \mathrm{~m}$ & $\mathrm{~L}_{3}, \mathrm{~m}$ & $\delta, \operatorname{deg}$ & $\mathrm{p}, \mathrm{MPa}$ \\
\hline $\mathrm{C}_{\mathrm{L}}$ & 3 & 0.4 & 0.4 & 14 & 8 \\
\hline $\mathrm{C}_{\mathrm{U}}$ & 4.1 & 1.5 & 1.5 & 21 & 25 \\
\hline
\end{tabular}

Table 3. Pareto optimal solutions - Stage I

\begin{tabular}{|c|c|c|c|c|c|c|c|c|c|c|}
\hline № & $f_{1}, \mathrm{~kg}$ & $f_{2} \times 10^{9},(\mathrm{Nm})^{2}$ & $f_{3} \times 10^{5} \mathrm{~N}$ & $L_{1}, \mathrm{~m}$ & $L_{2}, \mathrm{~m}$ & $L_{3}, \mathrm{~m}$ & $D, \mathrm{~m}$ & $h, \mathrm{~m}$ & $\delta, \mathrm{rad}$ & $p, \mathrm{MPa}$ \\
\hline 1 & 1082.8 & 8.02 & 5.69 & 3.680 & 0.949 & 0.452 & 0.18 & 1.8 & 0.278 & 11.19 \\
\hline 2 & 1015.6 & 11.54 & 6.49 & 3.378 & 0.826 & 0.443 & 0.18 & 1.6 & 0.343 & 12.74 \\
\hline 3 & 1049.2 & 16.69 & 6.26 & 3.551 & 0.839 & 0.523 & 0.18 & 1.7 & 0.359 & 12.31 \\
\hline 4 & 1116.4 & 19.45 & 5.60 & 3.799 & 1.003 & 0.499 & 0.18 & 1.9 & 0.341 & 11.00 \\
\hline 5 & 1183.6 & 17.64 & 4.99 & 4.075 & 1.140 & 0.504 & 0.18 & 2.1 & 0.316 & 9.80 \\
\hline 6 & 1150 & 27.89 & 5.55 & 3.979 & 1.066 & 0.478 & 0.18 & 2.0 & 0.246 & 10.90 \\
\hline 7 & 1150 & 34.53 & 5.42 & 3.909 & 1.109 & 0.448 & 0.18 & 2.0 & 0.316 & 10.65 \\
\hline 8 & 982 & 47.64 & 7.70 & 3.270 & 0.767 & 0.406 & 0.18 & 1.5 & 0.256 & 15.14 \\
\hline 9 & 948.4 & 48.54 & 8.26 & 3.105 & 0.707 & 0.402 & 0.18 & 1.4 & 0.323 & 16.22 \\
\hline 10 & 1435 & 5.31 & 5.33 & 3.881 & 0.990 & 0.509 & 0.20 & 1.9 & 0.328 & 8.49 \\
\hline
\end{tabular}

Table 4. Design variables bounds for Stage II

\begin{tabular}{|c|c|c|c|c|c|}
\hline & $\mathrm{L}_{1}, \mathrm{~m}$ & $\mathrm{~L}_{2}, \mathrm{~m}$ & $\mathrm{~L}_{3}, \mathrm{~m}$ & $\delta, \mathrm{deg}$ & $\mathrm{p}, \mathrm{MPa}$ \\
\hline $\mathrm{C}_{\mathrm{L}}$ & 3.1 & 0.7 & 0.4 & 14 & 8 \\
\hline $\mathrm{C}_{\mathrm{U}}$ & 4.1 & 1.2 & 0.53 & 21 & 16 \\
\hline
\end{tabular}

Table 5. Pareto optimal solutions - Stage II

\begin{tabular}{|c|c|c|c|c|c|c|c|c|c|c|}
\hline № & $f_{l}, \mathrm{~kg}$ & $f_{2} \times 10^{9},(\mathrm{Nm})^{2}$ & $f_{3} \times 10^{5} \mathrm{~N}$ & $L_{l}, \mathrm{~m}$ & $L_{2}, \mathrm{~m}$ & $L_{3}, \mathrm{~m}$ & $D, \mathrm{~m}$ & $h, \mathrm{~m}$ & $\delta, \mathrm{rad}$ & $p, \mathrm{MPa}$ \\
\hline 1 & 1015.6 & 3.41 & 6.12 & 3.391 & 0.802 & 0.474 & 0.18 & 1.6 & 0.360 & 12.04 \\
\hline 2 & 982 & 3.25 & 6.51 & 3.243 & 0.769 & 0.414 & 0.18 & 1.5 & 0.321 & 12.80 \\
\hline 3 & 1049.2 & 3.24 & 5.77 & 3.534 & 0.877 & 0.467 & 0.18 & 1.7 & 0.322 & 11.33 \\
\hline 4 & 1082.8 & 3.88 & 5.50 & 3.689 & 0.959 & 0.426 & 0.18 & 1.8 & 0.237 & 10.80 \\
\hline 5 & 1116.4 & 3.27 & 5.18 & 3.835 & 0.999 & 0.479 & 0.18 & 1.9 & 0.268 & 10.17 \\
\hline 6 & 948.4 & 9.23 & 7.31 & 3.103 & 0.707 & 0.403 & 0.18 & 1.4 & 0.328 & 14.36 \\
\hline 7 & 1150 & 3.801 & 4.96 & 3.982 & 1.041 & 0.528 & 0.18 & 2 & 0.290 & 9.74 \\
\hline 8 & 1183.6 & 9.96 & 4.89 & 4.096 & 1.131 & 0.503 & 0.18 & 2.1 & 0.289 & 9.61 \\
\hline
\end{tabular}

Table 6. Design variables bounds for Stage III

\begin{tabular}{|c|c|c|c|c|c|}
\hline & $\mathrm{L}_{1}, \mathrm{~m}$ & $\mathrm{~L}_{2}, \mathrm{~m}$ & $\mathrm{~L}_{3}, \mathrm{~m}$ & $\delta, \operatorname{deg}$ & $\mathrm{p}, \mathrm{MPa}$ \\
\hline $\mathrm{C}_{\mathrm{L}}$ & 3.1 & 0.75 & 0.4 & 14 & 9 \\
\hline $\mathrm{C}_{\mathrm{U}}$ & 4.1 & 1.13 & 0.53 & 21 & 14 \\
\hline
\end{tabular}

Table 7. Pareto optimal solutions - Stage III

\begin{tabular}{|c|c|c|c|c|c|c|c|c|c|c|}
\hline № & $\boldsymbol{f}_{1}, \mathrm{~kg}$ & $\boldsymbol{f}_{2} \times 10^{9},(\mathrm{Nm})^{2}$ & $\boldsymbol{f}_{3} \times 10^{5} \mathrm{~N}$ & $\boldsymbol{L}_{\boldsymbol{1}}, \mathrm{m}$ & $\boldsymbol{L}_{2}, \mathrm{~m}$ & $\boldsymbol{L}_{\boldsymbol{3}}, \mathrm{m}$ & $\boldsymbol{D}, \mathrm{m}$ & $\boldsymbol{h}, \mathrm{m}$ & $\boldsymbol{\delta}, \mathrm{rad}$ & $\boldsymbol{p}, \mathrm{MPa}$ \\
\hline 1 & 1049.2 & 3.22 & 5.76 & 3.538 & 0.892 & 0.435 & 0.18 & 1.7 & 0.280 & 11.32 \\
\hline 2 & 1015.6 & 3.21 & 6.13 & 3.386 & 0.839 & 0.414 & 0.18 & 1.6 & 0.295 & 12.05 \\
\hline 3 & 1082.8 & 3.47 & 5.47 & 3.689 & 0.949 & 0.447 & 0.18 & 1.8 & 0.259 & 10.75 \\
\hline 4 & 1082.8 & 3.46 & 5.48 & 3.688 & 0.949 & 0.446 & 0.18 & 1.8 & 0.258 & 10.75 \\
\hline 5 & 982 & 3.03 & 6.50 & 3.239 & 0.776 & 0.406 & 0.18 & 1.5 & 0.316 & 12.77 \\
\hline 6 & 1116.4 & 3.47 & 5.18 & 3.831 & 0.983 & 0.517 & 0.18 & 1.9 & 0.312 & 10.19 \\
\hline 7 & 1116.4 & 3.46 & 5.19 & 3.834 & 0.975 & 0.527 & 0.18 & 1.9 & 0.320 & 10.20 \\
\hline 8 & 1150 & 3.51 & 4.93 & 3.985 & 1.048 & 0.514 & 0.18 & 2.0 & 0.272 & 9.69 \\
\hline 9 & 1183.6 & 7.78 & 4.84 & 4.099 & 1.125 & 0.513 & 0.18 & 2.1 & 0.294 & 9.51 \\
\hline
\end{tabular}


Table 8. Compromise solutions for different weighting schemes

\begin{tabular}{|c|c|c|c|c|c|c|c|c|c|c|c|c|c|}
\hline № & $\mathrm{W}_{1}$ & $\mathrm{~W}_{2}$ & $\mathrm{~W}_{3}$ & $f_{l}, \mathrm{~kg}$ & $f_{2} \times 10^{9},(\mathrm{Nm})^{2}$ & $f_{3} \times 10^{5}, \mathrm{~N}$ & $L_{1}, \mathrm{~m}$ & $L_{2}, \mathrm{~m}$ & $L_{3}, \mathrm{~m}$ & $D, \mathrm{~m}$ & $h, \mathrm{~m}$ & $\delta, \mathrm{rad}$ & $p, \mathrm{MPa}$ \\
\hline 1 & $0 .(3)$ & $0 .(3)$ & $0 .(3)$ & 1082.8 & 3.47 & 5.47 & 3.689 & 0.949 & 0.447 & 0.18 & 1.8 & 0.259 & 10.75 \\
\hline 2 & 0.7 & 0.15 & 0.15 & 1015.6 & 3.21 & 6.13 & 3.386 & 0.839 & 0.414 & 0.18 & 1.6 & 0.295 & 12.05 \\
\hline 3 & 0.15 & 0.7 & 0.15 & 1049.2 & 3.22 & 5.76 & 3.538 & 0.892 & 0.435 & 0.18 & 1.7 & 0.280 & 11.32 \\
\hline 4 & 0.15 & 0.15 & 0.7 & 1116.4 & 3.47 & 5.18 & 3.831 & 0.983 & 0.517 & 0.18 & 1.9 & 0.312 & 10.19 \\
\hline 5 & 1 & 0 & 0 & 982 & 3.03 & 6.50 & 3.239 & 0.776 & 0.406 & 0.18 & 1.5 & 0.316 & 12.77 \\
\hline 6 & 0 & 1 & 0 & 982 & 3.03 & 6.50 & 3.239 & 0.776 & 0.406 & 0.18 & 1.5 & 0.316 & 12.77 \\
\hline 7 & 0 & 0 & 1 & 1183.6 & 7.78 & 4.84 & 4.099 & 1.125 & 0.513 & 0.18 & 2.1 & 0.294 & 9.51 \\
\hline
\end{tabular}

The vectors containing the discrete values for the standardized diameters and strokes of the hydraulic cylinders are taken from Table 1:

$$
D \in\left\{\begin{array}{l}
0.1,0.125,0.14,0.16,0.18, \\
0.20,0.22,0.25,0.28,0.32
\end{array}\right\} m
$$

and

$$
h \in\left\{\begin{array}{l}
1,1.1,1.2,1.3,1.4,1.5,1.6,1.7,1.8,1.9, \\
2.0,2.1,2.2,2.3,2.4,2.5,2.6,2.7
\end{array}\right\} m .
$$

By the conducted numerical experiment at this stage, 488 feasible points are found. In Figure 3a) they are shown in the 3D objective functions space together with the points belonging to the Pareto front. The Pareto front determined for the first stage contains 10 points for which objective functions values and its corresponding set of design variables are shown in Table 3. It must be noted that the ratio of the feasible points and the number of trial points is equal to $4.8 \times 10^{-8}$, which points out that the problem is difficult to solve due to the imposed very restrictive constraints;

Stage II. The analysis of the values of the objective functions and design variables for the obtained Pareto front at Stage I (see Table 3) makes it possible to narrow the intervals of change of the variables. The accepted bounds of the continuous design variables for Stage II are shown in Table 4.

The sets of the values of the discrete variables are reduced to $h \in\{1.4,1.5,1.6,1.7,1.8,1.9,2.0,2.1\} m$ and $D \in\{0.18,0.20\} m$.

At this stage, a numerical experiment with $5 \times 10^{9}$ trial points is conducted. The number of the feasible points is 10582 whose number is much greater than the points obtained at Stage I. The ratio of the feasible points and the number of trial points is equal to $2.12 \times 10^{-6}$, which means that the procedure of determination of feasible points is more effective than during Stage I. The obtained feasible space and Pareto front points are shown in Figure 3b), and the numerical values for the Pareto front are shown in Table 5. As one can see, the value of the piston diameter $D$ is equal to $0.18 \mathrm{~m}$ for all points in the Pareto front and thus this value can be considered optimal;

Stage III. Based on the results for Stage II, Table 6 shows the accepted bounds of the continuous design variables.

The sets of the values of the discrete variables are reduced to $h \in\{1.4,1.5,1.6,1.7,1.8,1.9,2.0,2.1\} m$ and $D \in\{0.18\} m$.
From the conducted numerical experiment with $5 \times 10^{9}$ trial points, 4557 feasible points are obtained. The feasible points and the Pareto front are shown in Figure $3 \mathrm{c}$ ) and the numerical values of the points belonging to the Pareto front are shown in Table 7.

As one can see from Tables 3, 5 and 7, narrowing the limits of the variables during the different stages leads to an improvement in the values of the solutions belonging to the Pareto front. The objective functions have different sensitivity - the value of criterion $f_{2}$ has the biggest improvement, the value of the objective function $f_{3}$ is less improved, and the value of $f_{l}$ has not changed.

Table 8 shows the optimal solutions calculated according to (34) for seven different combinations of the weighting factors. As one can see the optimal solution strongly depends on the chosen values of the weighting coefficients. In the first combination of weights, it is assumed that all objective functions are of equal importance, i.e. $w_{1}=w_{2}=w_{3}=0 .(3)$. In the combinations №2, №3 and №4, a higher priority is given to each of the three objective functions through assigning higher values of the corresponding weighting factor. The combinations №5, №6 and №7 present absolute minimums of the three objective functions.

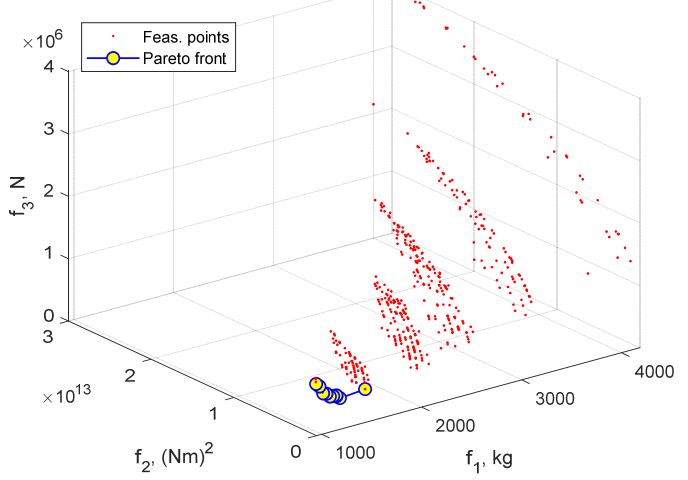

a)

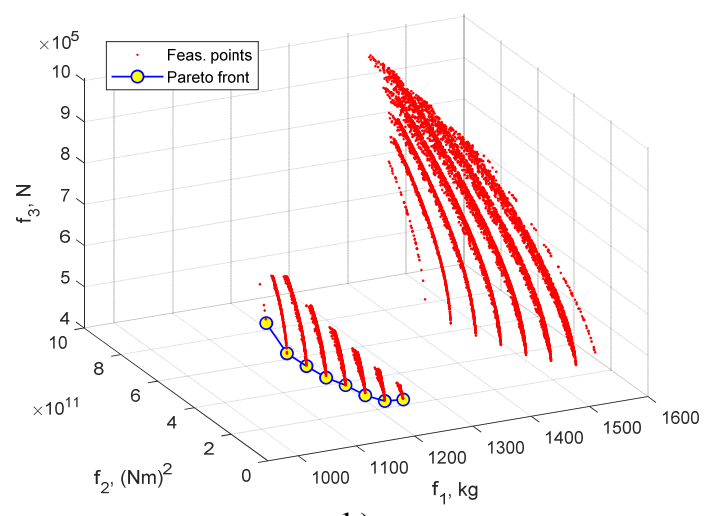

b) 


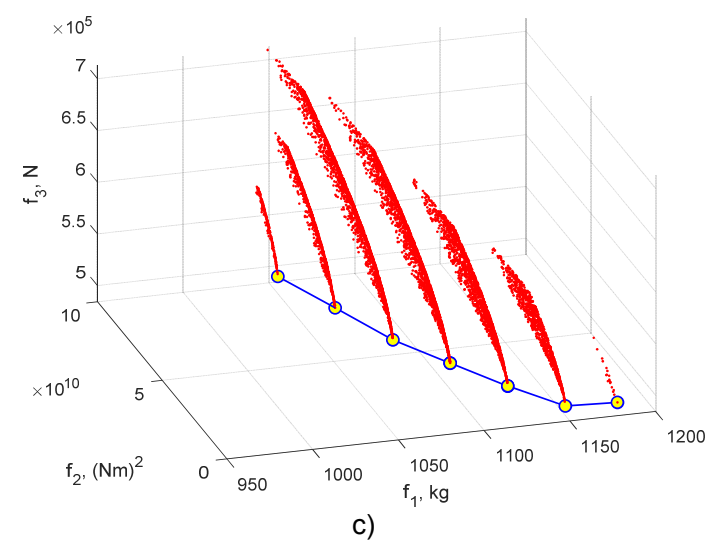

Figure 3. The feasible points and Pareto front for: a) Stage I; b) Stage II; c) Stage III

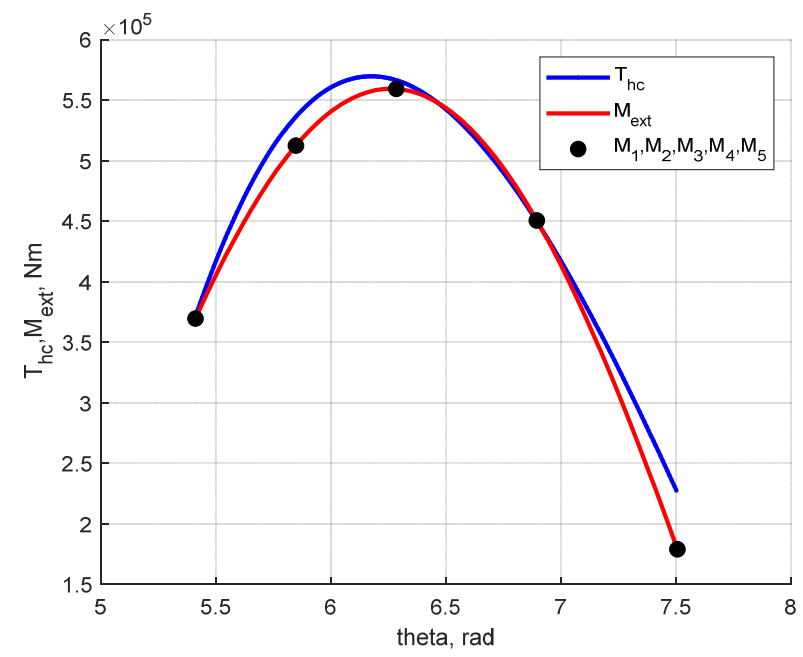

Figure 4. Moments $T_{h c}(\theta)$ and $M_{\text {ext }}(\theta)$ for solution №5 from Table 8

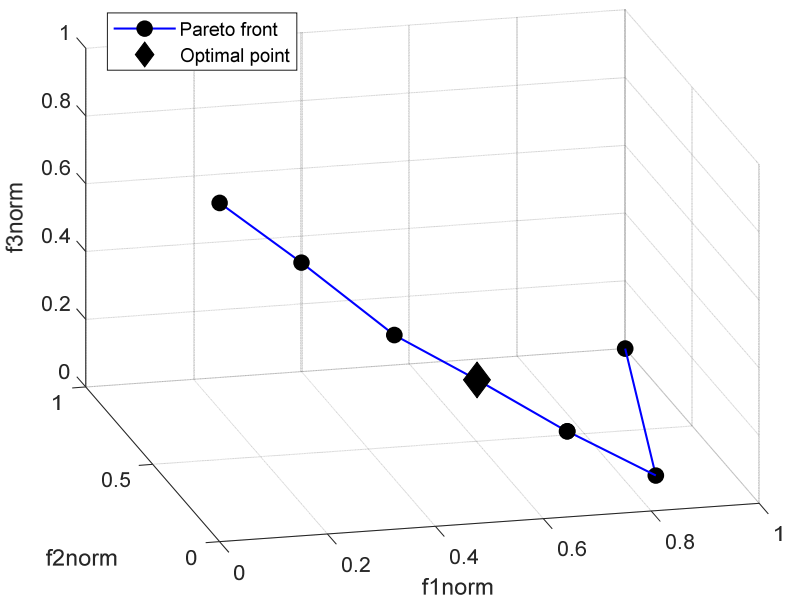

Figure 5. The normalized Pareto front and the optimal point for solution №5 from Table 8

Although at the present stage the obtained solutions can be considered acceptable, the values of the design variables for every single solution can serve as initial points for further refinement. To do this, the obtained values of the discrete variables are fixed and an additional searching in a small region, including the obtained values of the continuous variables is performed, i.e. an additional refinement of the attachment points of the selected hydraulic cylinder is performed. The values thus obtained for solution №5 from Table 8 are as follows: $f_{l}=982 \mathrm{~kg}, f_{2}=2.84 \times 10^{9} \quad(\mathrm{Nm})^{2}$, $f_{3}=6.48 \times 10^{5} \mathrm{~N}, D=0.18 \mathrm{~m}, h=1.5 \mathrm{~m}, L_{l}=3.241 \mathrm{~m}$, $L_{2}=0.764 \mathrm{~m}, L_{3}=0.425 \mathrm{~m}, \delta=0.339 \mathrm{~m}, p=12.73 \mathrm{MPa}$. As one can see, there is a more noticeable improvement for the value of the objective function $f_{2}$.

Fig. 6 depicts a scaled geometrical layout of the mechanism for solutions №1 and №5 of Table 8. It demonstrates that, by giving different weights to different objective functions, the mechanism dimensions can be adjusted. It can be seen that sol. №5 has smaller dimensions than sol. №1, and the hydraulic cylinder is lighter, but on the other hand the force in the hydraulic cylinder is greater in solution №5.

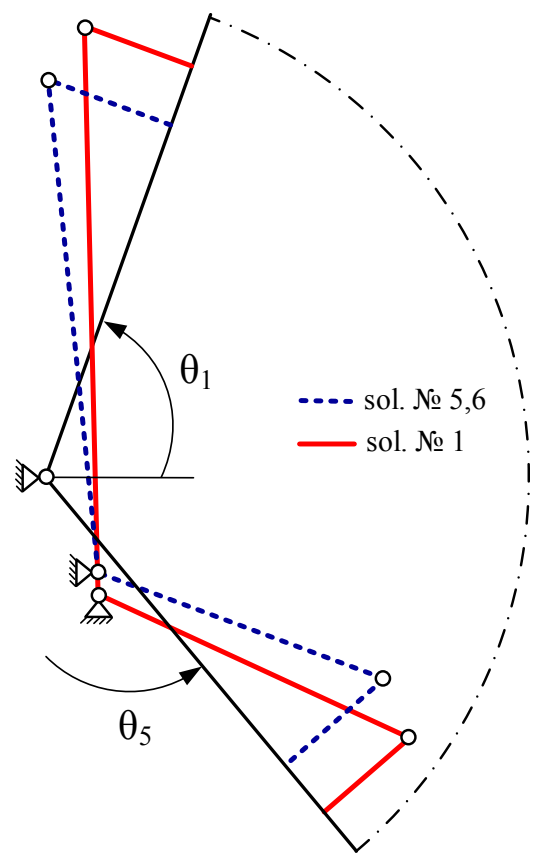

Figure 6. Scaled geometric layout of the attachment points for solutions № 1 and 5 from Table 8

The solutions №5 and №6 of Table 8 deserves special attention since they simultaneously have a minimum of the objective functions $f_{l}$ and $f_{2}$ equal to $982 \mathrm{~kg}$ and $3.03 \times 10^{9}(\mathrm{Nm})^{2}$ respectively, while the function $f_{3}$ has a maximum of $6.5 \times 10^{5} \mathrm{~N}$. From a practical point of view, this solution does not differ much from the solution №1 from Table 8 with equal importance of all objective functions, and it is also acceptable for implementation in a real-world structure. Figure 4 shows the graphs of the moments $T_{h c}(\theta)$ and $M_{\text {ext }}(\theta)$ for solution №5, while Figure 5 depicts the normalized Pareto front and the optimal point for the same case. As one can see, the constraints $g_{5}(\mathbf{x}) \div g_{9}(\mathbf{x})$ are completely satisfied and the difference between the two curves is acceptable.

The verification of the developed optimization model is conducted using the $\varepsilon$-constraint method [22]. To preserve the multiobjective character of the optimization problem is used as an objective function $f_{2} \rightarrow \min$ and the objective functions $f_{l}$ and $f_{3}$ are used as additional constraints and are added to the set of constraints (28), i.e. $f_{1^{-}}-1000 \leq 0$ and $f_{3}-7 \times 10^{5} \leq 0$. Using a nonlinear programming solver based on genetic algorithms, the single objective optimization problem is solved and the following optimal values of the design variables are obtained: $L_{1}=3.244 \mathrm{~m}, L_{2}=0.761 \mathrm{~m}$, $L_{3}=0.427 \mathrm{~m}, \delta=0.337 \mathrm{rad}, p=13.27 \mathrm{MPa}, D=0.18 \mathrm{~m}$, 
$h=1.5 \mathrm{~m}$. The obtained values for the objectives are $f_{1}=982 \mathrm{~kg}, f_{2}=2.72 \times 10^{9}(\mathrm{Nm})^{2}$ and $f_{3}=6.42 \times 10^{5} \mathrm{~N}$. As one can see, the differences in the objective functions compared to the refined solution №5 from Table 8 are negligible.

\section{CONCLUSION}

In the designer's practice, the process of selecting a hydraulic cylinder for hydraulically actuated mechanisms is inherently iterative. The designer of such mechanisms repeatedly uses analytical and graphical techniques to select a suitable standardized hydraulic cylinder and checks whether the resulting solution meets predefined requirements. To some extent, the design process is also intuitive and based on the experience of the designer. Using trial and error method it is challenging to achieve an optimal selection that cannot be improved or an improvement can be achieved with a large expenditure of time and effort.

The developed method for optimization synthesis of hydraulically driven mechanisms allows multiobjective optimal selection of a standardized hydraulic cylinder satisfying preset geometric and force requirements. By applying the multi-stage Monte Carlo method the Pareto front is obtained. It contains several compromise solutions that are Pareto-optimal. The choice of a certain solution from the Pareto set is made based on Salukvadze's criterion by setting proper weighting factors for each of the objective functions. Although the Monte Carlo method is computationally inefficient, with reasonable effort optimal and suboptimal solutions can be obtained that can be implemented in real-world machines. A great advantage of this approach is its interactivity - in the process of optimization, the designer can adjust the intervals of change of the design variables and constraints, as well as not to comply with their type - continuous or discrete.

\section{REFERENCES}

[1] Simionescu, P. A. and Beale, D.: Optimum Synthesis of the Four-Bar Function Generator in Its Symmetric Embodiment: The Ackermann Steering Linkage, Mech. Mach. Theory, Vol. 37, No. 12, pp. 1487-1504, 2002.

[2] Bulatović, R.R. and Đorđević S.R.: Optimal synthesis of a four-bar linkage by method of controlled deviation, Theoretical and Applied Mechanics, Vol. 31, No. 3-4, pp. 265-280, 2004.

[3] Aboulissane, B., Bakkali, L. and Bahaoui J.: Workspace analysis and optimization of the parallel robots based on computer-aided design approach, Facta Universitatis Series: Mechanical Engineering, Vol. 18, No. 1, pp. 79-89, 2020.

[4] Zou, Z., Chen, J. and Pang, X.: Optimum dimensional synthesis for the working mechanism of a hydraulic excavator to improve the digging performance, Proceedings of the Institution of Mechanical Engineers, Part K: Journal of Multibody Dynamics, Vol. 232 No. 3, pp. 357-370, 2018.
[5] Gerasimov, Y. Y and Siounev, V.S.: Forest Machinery Crane Compound Scheme Synthesis: Optimization of Hydraulic Cylinder Operating Mechanisms, Journal of Forest Engineering, Vol. 11, No. 1, pp.73-79, 2000.

[6] Papadopoulos, E. and Davliakos, I.: A systematic methodology for optimal component selection of electrohydralic servosystems, International Journal of Fluid Power, Vol. 5, No. 3, pp.15-24, 2004.

[7] Simionescu, P.A.: Optimum synthesis of oscillating slide actuators for mechatronic applications, Journal of Computational Design and Engineering, Vol.5, No. 2, pp.215-231, 2018.

[8] Janosevic, D.: Optimalna sineza pogonskih mehanizama hidraulickih bagera, $\mathrm{PhD}$ thesis, Masinski fakultet Univerziteta u Nisu, Nis, 1997.

[9] Jovanovic, V., Janosevic, D. and Pavlovic, J.: Analysis of the influence of the digging position on the loading of the slewing platform bearing in hydraulic excavators, Facta Universitatis Series: Mechanical Engineering, doi: 10.22190/fume190225020j (In print)

[10] Rexroth Bosch group. Hydraulic cylinder Mill type RE 17326,Version: 2013-06, 2013.

[11]Huang, M.W. and Arora, J.S.: Optimal design of steel structures using standard sections, Structural Optimization, Vol.14, pp. 24-35, 1997.

[12] Omidinasab, F. and Goodarzimehr, V.: A Hybrid Particle Swarm Optimization and Genetic Algorithm for Truss Structures with Discrete Variables, J. Appl. Comput. Mech., Vol. 6, No. 3, pp.593-604, 2020.

[13] Arora, J.S.: Methods for discrete variable structural optimization, in: S.A. Burns (Ed.), Recent Advances in Optimal Structural Design, Technical Committee on Optimal Structural Design, ASCE, Reston, VA, pp. 1-40., 2002.

[14] Arora, J.S. and Tseng, C.H.: Interactive design optimization, Engineering Optimization, Vol. 13, No. 3, pp.173-188,1988.

[15] Cabrera, J., Simon, A., Prado, M.: Optimal synthesis of mechanisms with genetic algorithms, Mechanism and Machine theory, Vol. 37, No. 10, pp. 1165-1177, 2002.

[16] Wolfram Research, Inc., Mathematica, Version 12.2, Champaign, IL, 2020.

[17] Kroese, D.P. et al.: Handbook of Monte Carlo Methods, Wiley Series in Probability and Statistics, John Wiley and Sons, New York, 2011.

[18] Madić, M., Kovačević, M and Radovanović, M.: Application of multi-stage Monte Carlo method for solving machining optimization problems, International Journal of Industrial Engineering Computations, Vol. 5, No. 4, pp. 647-659, 2014.

[19]Bakir, M. A. and Byrne, M. D.: An application of the multi-stage Monte Carlo optimization algorithm to aggregate production planning, International Journal of Production Economics, Vol. 35, No. 1-3, pp. 207-213, 1994. 
[20] Statnikov, R., Bordetsky, A., Matusov, J., Sobol', I. and Statnikov, A.: Definition of the feasible solution set in multicriteria optimization problems with continuous, discrete, and mixed design variables, Nonlinear Analysis: Theory, Methods \& Applications, Vol.71, No.12, pp. e109-e117, 2009.

[21]Cheshankov, B., Ivanov, I., Vitliemov, V. and Koev, P.: PSI-method multi-criteria optimization contracting the set of trade-off solutions, In: Proceedings of the International Conference on Systems Science, Vol.1, pp.281-288, 2004,

[22]Fragassa, C., Minak, G. and Pavlovic, A.: Measuring deformations in the telescopic boom under static and dynamic load conditions. Facta Universitatis Series: Mechanical Engineering, Vol. 18, No. 2, pp. 315 - 328, 2020.

[23] Marler, R. and Arora, J.: Survey of multi-objective optimization methods for engineering, Struct Multidisc Optim, Vol. 26, pp. 369-395, 2004.

[24] Mitrev, R. and Marinković, D: Numerical study of the hydraulic excavator overturning stability during performing lifting operations, Advances in Mechanical Engineering, Vol. 11, No. 5, 2019.

[25] Rašuo, B., Vidanović, N., Kastratović, G. and Mirkov, N.: Aerodynamic-thermal/structural design optimization of missile fin configuration during supersonic flight condition, Proc. Appl. Math. Mech., Vol. 20, No. 1: e202000220, 2021.

[26]Kumar, J. and Verma, R.: Experimental Investigations and Multiple criteria Optimization during Milling of Graphene Oxide (GO) doped epoxy/CFRP Composites Using TOPSIS-AHP hybrid Module, FME Transactions, Vol. 48, No. 3, pp.628-635, 2020.

[27] Pamucar, D.: Normalized weighted Geometric Dombi Bonferoni Mean Operator with interval grey numbers: Application in multicriteria decision making, Reports in Mechanical Engineering, Vol. 1, No. 1, pp. 44-52, 2020.
[28] Pavlovic, A. and Fragassa, C.: Geometry optimization by fem simulation of the automatic changing gear, Reports in Mechanical Engineering, Vol. 1, No. 1, pp. 199-205, 2020.

[29] Vidanović, N., Rašuo, B., Kastratović, G., Grbović, A., Puharić, M. and Maksimović, K., Multidisciplinary Shape Optimization of Missile Fin Configuration Subject to Aerodynamic Heating, Journal of Spacecraft and Rockets, Vol. 57, No. 3, pp. 510-527, 2020.

[30] Salukvadze, M.: Vector-Valued Optimization Problems in Optimal Control Theory, Academic Press, New York, 1979.

\section{ВИШЕКРИТЕРИЈУМСКИ ОПТИМАЛНИ ИЗБОР ХИДРАУЛИЧКОГ ЦИЛИНДРА ЗА ПОГОНСКЕ МЕХАНИЗМЕ}

\section{Р.П. Митрев, Т.С. Тодоров}

Рад приказује синтетизовани метод оптимизације примењен код хидраулички активираног погонског механизма. Развијен је математички модел механизма помоћу једначине затварања вектора. На основу функционалности механизма дефинисан је скуп захтева, геометријских и сила/момент, који се морају задовољити адекватним избором стандардизованог хидрауличког цилиндра и тачака везивања. Задатак вишециљне оптимизације дизајна је дефинисан помоћу три објективне функције код којих се тражи минимум - маса хидрауличког цилиндра, квадрат укупног одступања момента цилиндра из унапред одређених вредности спољашњих момената и сила цилиндра. Задатак оптимизације се разматра као проблем оптимизације мешовитих променљивих и нелинеарних ограничених вредности и садржи 5 непрекидних и 2 дискретне променљиве, док се Монте Карло метод користи за решавање проблема. Коришћењем различитих шема пондерисања добијено је неколико Парето оптималних решења. 